\title{
Pediatric Brain Abscess Clinical Profile, Management and Outcome at Tertiary Care Centre in Nepal
}

\author{
Prakash Kafle, ${ }^{1}$ Mohan Raj Sharma, ${ }^{2}$ Sushil Krishna Shilpakar, ${ }^{2}$ Gopal Sedain, ${ }^{2}$ Amit Pradhanang, ${ }^{2}$ Ram \\ Kumar Shrestha, ${ }^{3}$ Binod Raj Bhandari, ${ }^{2}$ Babita Khanal ${ }^{4}$ \\ ${ }^{1}$ Department of Neurosurgery, Nobel Medical College \& Teaching Hospital, Biratnagar, Nepal, ${ }^{2}$ Department of \\ Neurosurgery, Tribhuvan University Teaching Hospital Kathmandu Nepal, ${ }^{3}$ Department of Neurosurgery, Om Hospital \\ and Research centre ,Kathmandu Nepal, ${ }^{4}$ Department of Paediatric Medicine, Nobel Medical College \& Teaching \\ Hospital, Biratnagar, Nepal.
}

\section{ABSTRACT}

Background: Brain abscess in pediatric population is serious life threatening problem. Many risk factors are associated with this entity like congenital heart disease, ear infection and immunocompromised state. Early diagnosis and treatment with minimal invasive procedure has good outcome. Materials and Methods: This is a hospital based cross-sectional study conducted at institute of Medicine (IOM), Tribhuvan University Teaching Hospital Kathmandu, Nepal over the period of 3 years between September 2014 to August 2017. Clinical profile, management and outcome were analyzed. Results: A total of 27 cases were taken for the surgical management in the present study. There were 18 male and 9 female with the male to female ratio of 2:1. Mean age of the study population was 7.08 years. Otogenic Abscess was the most common $37.03 \%(\mathrm{n}=10)$ and the temporal lobe was the most common site $(37.5 \%)$. Headache was the most common clinical presentation seen in $74.07 \%$. All the cases were initially managed with the burrhole and aspiration. Only $14.8 \%(\mathrm{n}=4)$ of cases subsequently required surgical excision of the abscess wall. Only $18.5 \%(n=5)$ of the cases required multiple session aspiration. Positive culture was seen in $25.9 \%$ $(n=7)$. Pseudomonas aeruginosa and E.coli were the commonest organisms grown. Mortality rate was 3.7\%. Conclusion: Modern advances in radio imaging and multidisciplinary team involvement has decreased the morbidity and mortality.

Keywords: otogenic brain abscess; pediatric brain abscess; tubercular abscess.

\section{INTRODUCTION}

Brain abscesses in children is rare. ${ }^{1}$ Congenital heart disease, ear infection are the major risk factors for brain abscess formation and other risk factors are poor dental hygiene, complications from dental procedures, infancy, immune suppression, neurosurgical procedures such as implantation of ventriculoperitoneal shunts, penetrating skull injury, compound depressed skull fractures, congenital lesions of the head and neck. It can also be seen following complicated meningitis. Case reports of brain abscess following aspiration of esophageal foreign bodies, ${ }^{2}$ endoscopy ${ }^{3}$ and ocular trauma ${ }^{4}$ have been found. There are few reports of brain abscess after placement of dental braces. ${ }^{5}$ Exact incidence of brain abscess is variable with the average incidence of $8 \%$ of intra-cranial masses in developing countries. ${ }^{6}$ There have been recent advances in the radio imaging techniques in diagnosing brain abscess and so is the advance in management strategies hence reducing the case fatality rates.

\section{MATERIALS AND METHODS}

This study was carried out at institute of medicine (IOM), Tribhuvan University Teaching Hospital (TUTH) Kathmandu, Nepal. It is a hospital based cross-sectional study conducted from September 2014 to August 2017. Clinical profile, management and outcome were analyzed. Total of 27 study populations were identified. After proper evaluation radio imaging with contrast enhanced computed tomography of the head was performed as a initial diagnostic modalities. Sometimes, high resolution computed tomography (HRCT) of respected ear was done in indicated cases. Patients were initially managed with mannitol and dexamethasone with standard dose till the surgical intervention and tapered accordingly on the basis of clinical improvement which lasted not more than a week.

Correspondence: Dr. Prakash Kafle, Department of Neurosurgery, Nobel Medical College \& Teaching Hospital, Biratnagar, Nepal. Email: prakashkaflee@gmail.com . DOI: 10.3126/jcmsn.v14i2.20339. Article received: 2018-0618. Article accepted: 2018-06-26. 
Kafle et al. Pediatric brain abscess clinical profile, management and outcome at..

Phenytoin was given for all supratentorial abscesses for a minimum of 1 month and continued in patients with seizures for a period of 2 years. Our standard protocol was to do a burr hole and drainage of pus and get CT scan of the head done after one week. After drainage, obtained sample was sent for Gram stain and culture sensitivity. Vancomycin $15 \mathrm{mg} / \mathrm{kg}$ IV q8 hourly, Ceftriaxone $25 \mathrm{mg} / \mathrm{kg}$ IV in two divided doses and Metronidazole $15 \mathrm{mg} / \mathrm{kg}$ IV q8 hourly were the triple antibiotic of choice for empirical treatment and changed accordingly on the basis of culture sensitivity report for 6 weeks on oral basis. Imaging in the form of CT scan was repeated after a week and two weekly thereafter. However CT head was done in between the above period if indicated by the clinical status of the patient which was accessed on by fall in GCS of the patient by $\geq 2$ points in total. All the Patients were labeled as cured on the basis of radioimaging if no abscess cavity was found after six weeks.

\section{RESULTS}

Total of 27 cases were subjected for the study (18 male and 9 female). Male to female ratio was 2:1 and mean age was 7.08 years. Minimum age of study population was 4 months (Table 1 ).

\begin{tabular}{|llll|}
\hline \multicolumn{4}{|l|}{ Table 1. Demographic profile of the study } \\
population. \\
\hline Group & $\begin{array}{l}\text { Age range } \\
\text { (Years) }\end{array}$ & $\begin{array}{l}\text { Frequency } \\
\text { (n) }\end{array}$ & $\begin{array}{l}\text { Percentage } \\
\text { (\%) }\end{array}$ \\
1 & $0-5$ & 12 & 44.4 \\
2 & $6-10$ & 7 & 25.9 \\
3 & $11-16$ & 8 & 29.6 \\
\hline
\end{tabular}

Etiology: Ongoing ear infection in the form of chronic suppurative otitis media (CSOM) was the most common preceding cause of brain abscess in the study followed by cyanotic congenital heart disease mainly Tetralogy of Fallot. In about one fifth $(22.22 \%)$ of the cases $(n=6)$, the cause was not identified. Moreover, the detail work up for the immune status of the study population was not carried in the present study due to resource constrain. Brain abscesses were mostly due to CSOM ( $n=10)$ and Cardiogenic (Tetralogy of Fallot's (TOF)) in origin $(n=6)$. Other were tubercular abscess $(n=3)$ and few cases were due to animal bite $(\mathrm{n}=2)$. In $22.2 \%(\mathrm{n}=6)$ cases, cause was not identified (Table 2 ).

\section{Location}

Supratentorial abscess was predominant in 24 cases $(88.88 \%)$ and the remaining $11.12 \%(n=3)$ was

\begin{tabular}{|lcc|}
\hline \multicolumn{3}{l|}{ Table 2. Causes of brain abscess. } \\
\hline Etiology & Frequency & Percentage (\%) \\
CSOM & 10 & 37.03 \\
TOF & 6 & 22.2 \\
Tubercular & 3 & 11.11 \\
Animal bite & 2 & 7.40 \\
Idiopathic & 6 & 22.2 \\
Total & 27 & $100 \%$ \\
\hline
\end{tabular}

infratentorial. Temporal lobe was the most common site comprising $37.5 \%$. ( $\mathrm{n}=9)$ among the supra tentorial variant (Table 3 ).

\begin{tabular}{|lcc|}
\hline \multicolumn{3}{|c|}{ Table 3.a. Location of the brain Abscess. } \\
\hline Etiology & Frequency & Percentage (\%) \\
Supratentorial & 24 & 88.88 \\
Infratntorial & 3 & 11.12 \\
Total & $\mathrm{N}=27$ & $100 \%$ \\
\hline
\end{tabular}

\begin{tabular}{|lll|}
\hline \multicolumn{2}{|c|}{ Table 3.b. Supratentorial Abscess Location . } \\
\hline $\begin{array}{l}\text { Supratentorial } \\
\text { location }\end{array}$ & Frequency(n) & Frequency(n) \\
Temporal & 9 & 9 \\
Frontal & 6 & 6 \\
Multiple & 5 & 5 \\
Parietal & 4 & 4 \\
& Total & $\mathbf{2 4}$ \\
\hline
\end{tabular}

\section{Clinical presentation}

Headache was the most common presenting features (Table 4). Ear discharge or ear ache was the second most common clinical presentation seen in $37.03 \%(\mathrm{n}=10)$. The classic presentation of headache, fever and neurological deficits was seen in only $7.40 \%(n=2)$. Seizure was seen in $11.11 \%$ $(n=3)$. Two small babies presented with the history of poor feeding and one baby was brought with history of infected left frontal scalp wound with exposed brain parenchyma that had subdural

\begin{tabular}{|c|c|c|c|}
\hline ה & $\begin{array}{l}\text { Clinical } \\
\text { features }\end{array}$ & Frequency (n) & Percentage $(\%)$ \\
\hline 1 & Headache & 20 & 74.07 \\
\hline 2 & Ear Discharge & 10 & 37.03 \\
\hline 3 & Vomiting & 5 & 18.51 \\
\hline 4 & $\begin{array}{l}\text { Focal Neurologi- } \\
\text { cal deficits }\end{array}$ & -3 & 11.11 \\
\hline 5 & Seizure & 3 & 11.11 \\
\hline 6 & Fever & 2 & 7.40 \\
\hline 7 & $\begin{array}{l}\text { Altered } \\
\text { Sensorium }\end{array}$ & 1 & 3.70 \\
\hline
\end{tabular}


Kafle et al. Pediatric brain abscess clinical profile, management and outcome at.

empyema.

\section{Radiology}

Radiological evaluation with contrast enhanced Computed tomography was the initial diagnostic modality and magnetic resonance image (MRI) was done in selected cases of diagnostic dilemma. Typical appearances in CECT were a ring of iso- or hyperdense tissue, typically of uniform thickness with central low attenuation (fluid/pus) surrounding low density (vasogenic oedema). Peripheral enhancing lesions in the subdural and epidural spaces with or without air density was suggestive of subdural empyema and epidural abscess. Suppurative otitis media were suggested by destruction of middle ear and soft tissue density in

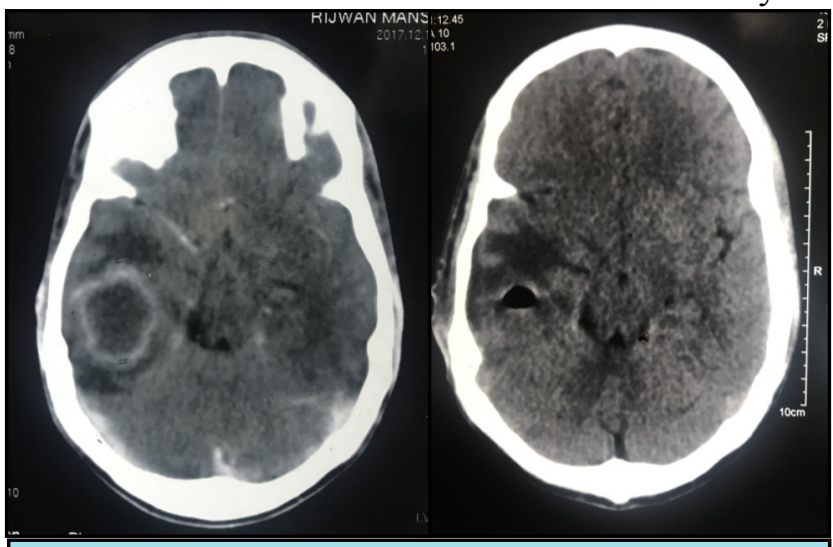

Figure 1a, 1b. Right and left .

the mastoid air cells.

\section{Management}

In the present study, total of 23 cases $(85.1 \%)$ had burrhole and drainage of abscess and only 4 cases $(14.8 \%)$ required major craniotomy and excision of abscess cavity. Five cases required multiple session aspiration ranging from 2-5 times. Total 10 cases had undergone modified radical mastoidectomy (MRM) in same setting. Of these MRM cases, 9 underwent burrhole and aspiration only and one needed major craniotomy and abscess excision. In two small babies of 4 month and 6 months age, with large brain abscess simple burrhole and continuous abscess drainage through the catheter placed into the abscess cavity was done which had good recovery after 5 days in one and after 7 days in another. There was minimal residual after repeat scan which subsequently resolved after 2 months. Craniotomy and subdural empyema was drained in those cases who had subdural empyema and epidural abscess $(\mathrm{n}=2)$. Craniotomy and excision of abscess was done in one and craniotomy and excision of abscess plus MRM was done in the same setting in other. The infected scalp with exposed brain tissue in case of another animal bite needed multiple sessions of debridement. Regular two weeks of intravenous and four weeks of oral antibiotics including anaerobic coverage were the standard treatment protocol. Few cases were treated with eight weeks of antibiotics. The surgical

\begin{tabular}{|c|c|c|c|}
\hline SN & Procedure & $\begin{array}{l}\text { Frequency I } \\
\text { (n) }\end{array}$ & $\begin{array}{l}\text { Percentage } \\
(\%)\end{array}$ \\
\hline 1 & Burrhole and aspiration & 12 & 44.44 \\
\hline 2 & $\begin{array}{l}\text { Burrhole and Aspiration }+ \\
\text { MRM }\end{array}$ & 9 & 33.3 \\
\hline 3 & $\begin{array}{l}\text { Burrhole and Continuous } \\
\text { drainage }\end{array}$ & 2 & 7.40 \\
\hline 4 & $\begin{array}{l}\text { Debridement and Subdura } \\
\text { empyema drainage }\end{array}$ & 2 & 7.40 \\
\hline 5 & $\begin{array}{l}\text { Craniotomy and Excision }+ \\
\text { MRM }\end{array}$ & 1 & 3.70 \\
\hline 6 & Craniotomy and Excision only & 1 & 3.70 \\
\hline & Total & 27 & \\
\hline
\end{tabular}

procedure is summarized in table 5 .

\section{Bacteriology:}

Culture positivity was seen in only $25.9 \%(n=7)$. In our series Pseudomonas aeruginosa was detected in 5 cases and E. coli was isolated in 1 case and multiple organisms were isolated in 1 case. Fungal and anaerobic culture was not done.

\section{Complications}

The mortality rate was $7.40 \% \quad(n=2)$. Thrombophelibitis of the extremities was the most common benign complication which resolved in all the cases with general measures. Other major complications like post operative facial nerve palsy which was seen in one case. It was a case of large temporal brain abscess with underlying cyanotic heart disease. He had undergone one session of burrhole and aspiration and had recollected abscess. $\mathrm{He}$ died because of the non cranial cause. Other complications are listed in table 6 .

\section{Outcome}

All the cases were followed up for minimum of three months with follow up rate of $81.4 \%$. All of

\begin{tabular}{|l|l|c|c|}
\hline \multicolumn{4}{|c|}{ Table 6: Complications. } \\
\hline $\begin{array}{l}\mathrm{S} \\
\mathrm{N}\end{array}$ & Complications & $\begin{array}{l}\text { Frequency } \\
(\mathrm{n})\end{array}$ & $\begin{array}{l}\text { Percent- } \\
\text { age (\%) }\end{array}$ \\
\hline 1 & Mortality & 2 & 7.40 \\
\hline 2 & Pyoventricle & 1 & 3.70 \\
\hline 3 & $\begin{array}{l}\text { Post MRM Facial Nerve } \\
\text { Palsy (Grade II-V) }\end{array}$ & 1 & 3.70 \\
\hline 4 & Pseudomeningocele & 1 & 3.70 \\
\hline 5 & Surgical Site Infection & 1 & 3.70 \\
\hline
\end{tabular}


them had good functional outcome for that age group. Superficial surgical site infection was noted in one case which resolved at six week of follow up. There was one case of facial palsy which did not resolved until follow up of three months.

\section{DISCUSSION}

Brain abscess accounts for major complication following ear infection. Clinical presentation varies in different patients, and all of the classic triad of fever, headache and focal deficit is rarely present. Features of raised intracranial pressure with or without localizing sign requires early imaging. ${ }^{8}$ Initial investigation of choice is Contrast enhanced CT of the head. ${ }^{9}$ Sometimes Magnetic resonance imaging (MRI), with or without diffusion-weighted (DWI) and apparent-diffusion coefficient (ADC) images, is of valuable diagnostic tool. MRI has positive predictive value of $98 \%$ and negative predictive value of $92 \% .{ }^{10}$ Cultures of blood and cerebrospinal fluid identify the causative pathogen in approximately one quarter of patients. In very few cases like with coexistence of meningitis, CSF analysis and cultures may be of some importance in diagnosing brain abscess However, it carries great risk of brain. ${ }^{11}$

There is no solid consensus on management of brain abscess. Therefore the treatment of every case individualizes depending on its locations, size, and stage. The aim of the treatment is early drainage of abscess by any means either minimal invasive or open surgery. There are new stereotactic techniques for drainage of brain abscess which helps when the size is less than $1 \mathrm{~cm}$ in diameter. ${ }^{12}$ Conservative treatment with broad spectrum antibiotics can also be considered in selected cases. Here in the present study we managed the cases with burr hole and aspiration of pus in majority. In few cases abscess wall excision was done. It was also indicated when multiple aspiration failed to resolve the abscess. Brain Abscess is seen $5-18 \%$ of the cases with congenital heart diseases especially Tetralogy of Fallot. ${ }^{13-14}$

There was male preponderance with ratio of $2: 1$. Headache was the most common presentation in the present study. These were comparable with the study by Sharma et al in the year $2013 .{ }^{15}$ Seizure was present in $12 \%$ of the cases which was $16 \%$ in a study by Furen Xiao. ${ }^{16}$ Similarly, ear infection was the major preceding illness predisposing to brain abscess in the present study (37.5\%). Supratentorial abscess was the most common in the present study comprising $88.88 \% .{ }^{17}$
The average duration of hospital stay was 28.5 days which are similar to the study by Sharma et al where the mean duration of hospital stay was 30.5 days. ${ }^{15}$ Major craniotomy use to be the surgical modality in the past, but with the advent of radiological imaging the simple burr hole and aspiration worked well and the outcome is comparable. In the present study 23 cases $(85.1 \%)$ had burrhole and aspiration with some primary control procedure avoiding major craniotomy and its risk. All most all the cases were diagnosed with the contrast CT of the head and only few cases required MRI brain. Culture of pus showed organism growth in 7 cases only $(25.9 \%)$. In a study done in India, only $20 \%$ culture growth was noted $\cdot{ }^{17}$ Lack of anaerobic culture and use of antibiotics before the sample being withdrawn may be the reasons behind the higher number of negative culture reports.

Hematoma into the abscess cavity, tract hematoma and intraventricular extension of abscess along with surgical site infection and sinus thrombosis were common complications. In the early days mortality rate was reported up to $60 \%(40-60 \%)$ however with modern neuro radio imaging and multi disciplinary approach the mortality has come down to $6-17 \% .{ }^{19-20}$ However GCS at the time of presentation is the best prognostic indicator. ${ }^{20}$ Intraventricular extension of abscess has higher mortality rate which has been reported up to $48 \%{ }^{21}$ There was $7.4 \%(n=2)$ mortality. Both the cases developed brain abscess following cyanotic congenital heart disease. Mortality was due to non cranial causes.

\section{CONCLUSION}

Otogenic infection is major risk factor for the brain abscess formation in pediatric age group. Children with raised ICP has limited time window between presentation and intervention. With advent of modern technology in the radio imaging mortality, helps in early diagnosis. Burr hole and aspiration seems a better option for surgical management. Major craniotomy and excision should be preserved for the multi loculated, recurrent, large abscess cavity only. Culture positivity is seen in few cases Long duration of parenteral or oral enteral broad spectrum antibiotics helps in early resolution. Multidisciplinary team involvement with otorhinolaryngology and treating the primary sources has shown better results.

Conflicts of interest: None 


\section{REFERENCES}

1. Jadavji T, Humphreys RP, Prober CG: Brain abscesses in infants and children. Pediatr Infect Dis 1985;4:394-98.

2. Roberts J, Bartlett AH, Giannoni CM, Valdez TA: Airway foreign bodies and brain abscesses: Report of two cases and review of the literature. Int J Pediatr Otorhinolaryngol 2008; 72:265-69.

3. Louie JP, Osterhoudt KC, Christian CW: Brain abscess following delayed endoscopic removal of an initially asymptomatic esophageal coin. PediatrEmerg Care 2000;16:102-5.

4. Bank DE, Carolan PL: Cerebral abscess formation following ocular trauma: a hazard associated with common wooden toys. PediatrEmerg Care 1993;9:285-88.

5. Wolf J, Curtis N: Brain abscess secondary to dental braces.Pediatr Infect Dis J 2008; 27:8485.

6. Sharma BS, Gupta SK, Khosla VK. Current concepts in the management of pyogenic brain abscess. Neurol India 2000; 48:105-11.

7. Bhatia R, Tandon PN, Banerji AK. Brain abscess an analysis of 55 cases.IntSurg $\mathrm{J}$ 1973;58:565-68.

8. Wanna GB, Dharamsi LM, Moss JR, Bennett ML, Thompson RC,Haynes DS. Contemporary management of intracranial complications of otitis media. OtolNeuroto 2010; 131:111-17.

9. Krivopalov AA, Yanov YK, Astashchenko SV, Shcherbuk AY, Artyushkin SA, Vakhrushev SG, et al. Features of Otogenic Intracranial Complications at the Present Stage. Vestnikkhirurgiiimeni I I Grekova 2015;174:6879

10. Reddy JS1, Mishra AM, Behari S, Husain M, Gupta V, Rastogi M, Gupta RK.The role of diffusion-weighted imaging in the differential diagnosis of intracranial cystic mass lesions: a report of 147 lesions. SurgNeurol 2006; 66:24650.

11. Jim KK, Brouwer MC, van der Ende A, van de Beek D. Cerebral abscesses in patients with bacterial meningitis. J Infect 2012; 64:236-8.
12. Barlas O, Sencer A, Erkan K, Eraksoy H, Sencer $\mathrm{S}$, Bayindir C. Stereotactic surgery in the management of brain abscess. SurgNeurol 1999;52:404-10.

13. Takeshita M1, Kagawa M, Yato S, Izawa M, Onda H, Takakura K, Momma K.Current treatment of brain abscess in patients with congenital cyanotic heart disease. Neurosurgery 1997; 41: 1270-1278

14. Shen H, Huo Z, Liu L, Lin Z. Stereotactic implantation of Ommaya reservoir in the management of brain abscesses. Br J Neurosurg 2011; 25:636-40.

15. Sharma Mohan R: Management of Pyogenic Brain Abscess in Children: Review of 50 Cases. Nepal Journal of Neuroscience 2013;10:61-67.

16. Furen Xiao, Ming-Yuan Tseng, Lee-Jene Teng et al.Brain abscess. clinical experience and analysis of prognostic factors. Surgical Neurology 2005;63: 442 - 50

17. Singh D, Gupta V, Singh AK, Sinha S. Evolution of otogenic brain abscess and management protocol. Indian Pediatrics 2001; 38 (2):169-73.

18. Kumar R, Pandey CK, bose N, Sahay S: Tuberculous brain abscess: clinical presentation, pathophysiology and treatment in children. Childs Nerv Syst 2002;18:118-23.

19. Kao PT, Tseng HK, Liu CP, Su SC, Lee CM. Brain abscess: clinical analysis of 53 cases. J Microbiol Immunol Infect 2003; 36:129-36.

20.Zhang C, Hu L, Wu X, Hu G, Ding X, Lu Y. A retrospective study on the aetiology, management, and outcome of brain abscess in an 11-year, single-centre study from China. BMC infectious diseases 2014;14:311.

21.Lee TH, Chang WN, Su TM, Chang HW, Lui CC, Ho JT, et al. Clinical features and predictive factors of intraventricular rupture in patients who have bacterial brain abscesses. J Neurol Neurosurg Psychiatry 2007; 78:303-9.

Citation: Kafle P, Sharma MR, Shilpakar SK, Sedain G, Pradhanang A, Shrestha RK, Bhandari BR, Khanal B. Pediatric brain abscess clinical profile, management and outcome at tertiary care centre in Nepal. JCMS Nepal. 2018;14(2):102-6. 